\title{
OPTIMIZATION OF NON-TRADITIONAL TUNED MASS DAMPER FOR DAMPED STRUCTURES UNDER HARMONIC EXCITATION
}

Onur ARAZ

Volkan KAHYA

Received: 10.02.2021; revised: 17.09.2021; accepted: 23.09.2021

\begin{abstract}
Tuned mass dampers (TMDs) are used to reduce dynamic vibrations of structures under environmental loads such as wind or seismic excitation. In this paper, the optimum design of nontraditional tuned mass dampers (NT-TMD) attached to a damped main structure under harmonic excitation was investigated. Unlike the traditional TMD, the damping element in NT-TMD is directly connected to the ground. In this study, the effectiveness of NT-TMD on the attenuation of vibrations on the damped main system under harmonic load is investigated. The optimum parameters of the NT-TMD are obtained by using the hybrid pattern search (HPS) technique. According to numerical results, it is seen that non-traditional TMD is more effective than traditional TMD in reducing vibration.
\end{abstract}

Keywords: Harmonic excitation, Optimum design, Performance, Tuned mass damper

\section{Harmonik Etki Altındaki Sönümlü Yapılar için Geleneksel Olmayan Ayarlı Kütle Sönümleyicinin Optimizasyonu}

Öz: Ayarlı kütle sönümleyiciler (AKS) rüzgâr ve sismik etkiler gibi çevresel yükler altındaki yapıların titreşimlerinin azaltılmasında kullanılmaktadır. Bu yazıda, harmonik etki altındaki sönümlü bir ana yapıya eklenen geleneksel olmayan ayarlanmış kütle sönümleyicilerin optimum tasarımı araştırılmıştır. Geleneksel AKS'den farklı olarak, sönüm elamanı direk olarak yere bağlanmaktadır. Geleneksel olmayan AKS'nin optimum parametreleri hibrit model arama tekniği kullanılarak elde edilmiştir. Numerik sonuçlar titreşim azaltılmasında geleneksel olmayana AKS'nin geleneksel AKS'ye göre daha etkili olduğu görülmektedir.

Anahtar Kelimeler: Harmonik etki, Optimum tasarım, Performans, Ayarlı kütle sönümleyici

\footnotetext{
* Gümüşhane University, Faculty of Engineering and Natural Sciences, Department of Civil Engineering, 29100, Gümüşhane

** Karadeniz Technical University, Faculty of Engineering, Department of Civil Engineering, 61080, Trabzon

Corresponding Author: Onur Araz (onuraraz29@hotmail.com)
} 


\section{INTRODUCTION}

Recently, various control systems have been used frequently to reduce vibrations on real structures (Esen and Koc, 2015; Koc, 2020 a,b; Araz and Kahya, 2021). Traditional and nontraditional TMDs have an easy-to-maintain and low cost unlike other types of system. Thus, there is a potential for TMDs to be used effectively in reducing different dynamic responses on the real structures.

The first TMD invented by Frahm (1909) without damping element had an effect in a narrow frequency range. Later, Ormondroyd and Den Hartog (1928) studied the classical TMD which has a mass system, a damping element and a spring element. Then, Den Hartog (1956) derived the optimum tuning parameters for TMD using the fixed-points theory. After these pioneering works, different methods for the optimum design of the TMD have been presented to minimize the dynamic vibrations of structures under different external excitations (Warburton, 1982; Fujino and Abe, 1993; Tsai, 1995; Jangid, 1999; Asami et al., 2002; Li, 2002; Bakre and Jangid, 2004; Marano et al., 2007; Marano and Greco, 2011; Nigdeli and Bekdas, 2014; Matta, 2015; Yazdi et al., 2016; Mate et al., 2017; Kahya and Araz, 2017; Dell'Elce et al., 2018; Mrabet et al., 2018; Araz and Kahya, 2018; Yucel et al., 2019; Kahya and Araz, 2019; Araz, 2020; Araz and Kahya, 2020; Ruge and Wagner, 2020).

NT-TMD devices are firstly studied by Ren (2001) and Liu and Liu (2005). In these studies, the dynamic behavior of the main structure subjected to harmonic load effect is reduced by using NT-TMD. Wong and Cheung (2008) investigated the control performance of a NT-TMD attached to main system under ground motion. The effectiveness of a NT-TMD in reducing the peak vibration velocity of the structure due to harmonic load is investigated by Cheung and Wong (2009). They also presented mathematical formulation for obtaining optimal parameters of a NT-TMD to reduce the resonant vibration amplitude and the total vibration energy of the structure system (Cheung and Wong, 2011a, b). Yuan et al. (2018) developed an experimental system to obtain the control performance of the NT-TMD.

When damping is existing at the main structure, there are too little research on the nontraditional tuned mass dampers. Liu and Coppola (2010) obtained the performance of NT-TMD by using sequential simplex method and Chebyshev's equi-oscillation theorem. Anh and Nguyen (2014) investigated the effectiveness of the NT-TMD by using approximate analytical solution for damped structure under external excitation. Anh et al. (2016) presented new method for obtaining the tuning parameters of a NT-TMD.

Unlike previous studies, the optimum parameters of NT-TMD are obtained for a damped main system instead of an undamped main system subjected to harmonic excitation. The tuning parameters of a NT-TMD are obtained by using the hybrid pattern search (HPS) technique which depends on the pattern search (PS) and genetic algorithm (GA). Although PS is widely used in the solution of different engineering problems, it is rarely used in the optimization of the tuned mass dampers. Therefore, it is preferred in the solution of the optimization problem in this study. However, no previous works have investigated the relationship between the robustness and the design parameters of a NT-TMD and TMD systems. The above state of the art leads to the motivation for further investigating the NT-TMD in this paper. In this respect, NT-TMD has been applied to a damped single degree of freedom (sdof) system due to harmonic excitation. Then, we compared the results obtained by HPS technique with those obtained by other methods and evaluated the control performance of these two available devices (i.e. NT-TMD and TMD). Therefore, this work is organized as follows. section 2 provides a detailed formulation of the problems being addressed, and section 3 discusses the optimization problem and optimal parameters in detail. Then, section 4 provides some numerical examples, followed by discussions and conclusions in section 5 . 


\section{MATHEMATICAL MODELING}

\subsection{Traditional TMD}

A sdof damped main system attached with a TMD or NT-TMD is presented in Fig. 1 (a). With an excitation force $f_{0} \sin (\omega t)$ exerted on the main structure, the dynamics of the two dof system in Fig. 1 (a) can be described by the equations of motion:

$$
m_{s} \ddot{x}_{s}+c_{s} \dot{x}_{s}+c_{t}\left(\dot{x}_{s}-\dot{x}_{t}\right)+k_{s} \dot{x}_{s}+k_{t}\left(\dot{x}_{s}-\dot{x}_{t}\right)=f_{0} \sin (\omega t)
$$

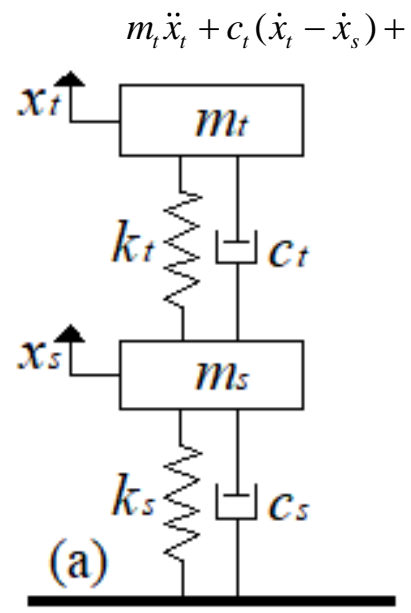

\section{Figure 1:}

TMD and NT-TMD attached to main structure, respectively

where the subscripts $t$ and $s$ are the TMD and main system, respectively. The mass, damping and stiffness coefficients are indicated by $m, c$ and $k$, respectively. $\omega$ and $f_{0}$ are the frequency and amplitude of the external force respectively.

The dynamic magnification factor (DMF) for the displacement of the structure is given as follows (Asami et al., 2002)

$$
D M F=\sqrt{\frac{\left(2 \alpha \beta \xi_{t}\right)^{2}+\left(\alpha^{2}-\beta^{2}\right)^{2}}{a^{2}+b^{2}}}
$$

where

$$
\begin{aligned}
& \beta=\frac{\omega}{\omega_{s}}, \quad \alpha=\frac{\omega_{t}}{\omega_{s}}, \quad \xi_{s}=\frac{c_{s}}{2 m_{s} \omega_{s}}, \quad \xi_{t}=\frac{c_{t}}{2 m_{t} \omega_{t}}, \quad \mu=\frac{m_{t}}{m_{s}} \\
& a=\left[2 \beta \xi_{s}\left(\alpha^{2}-\beta^{2}\right)+2 \alpha \beta \xi_{t}\left(1-\beta^{2}-\mu \beta^{2}\right)\right] \\
& b=\left[\alpha^{2}-\left(1+4 \alpha \xi_{s} \xi_{t}+\alpha^{2}+\mu \alpha^{2}\right) \beta^{2}+\beta^{4}\right]
\end{aligned}
$$

where the tuning ratio, the mass ratio, the damping ratio and the natural frequency of the TMD are indicated by $\alpha, \mu, \xi_{t}$ and $\omega_{t}$, respectively. The natural frequency of the main system and the forced frequency ratio are indicated by $\omega_{s}$ and $\beta$, respectively. 
For TMD device, the optimum tuning parameters for undamped main system are determined from Eq. (5) (Den Hartog, 1956)

$$
\xi_{t}=\sqrt{\frac{3 \mu}{8(1+\mu)}} \quad \alpha=\sqrt{\frac{1}{1+\mu}}
$$

\subsection{Non-Traditional TMD}

A sdof damped structure attached with a NT-TMD is presented in Fig. 1 (b). With an excitation force $f_{0} \sin (\omega t)$ exerted on the main structure, the dynamics of the two dof system in Fig. 1 (b) can be described by the equations of motion:

$$
\begin{gathered}
m_{s} \ddot{x}_{s}+c_{s} \dot{x}_{s}+k_{s}\left(\dot{x}_{s}+\dot{x}_{t}\right)-k_{t} \dot{x}_{t}=f_{0} \sin (\omega t) \\
m_{t} \ddot{x}_{t}+c_{t} \dot{x}_{t}+k_{t}\left(\dot{x}_{t}-\dot{x}_{s}\right)=0
\end{gathered}
$$

where the mass, damping and stiffness coefficients are indicated by $m, c$ and $k$ respectively. The subscripts $t$ and $s$ are the NT-TMD and main structure, respectively. $\omega$ and $f_{0}$ denote the frequency and amplitude of the external force, respectively.

DMF of the structure for the displacement is given as follows (Anh and Nguyen, 2014)

$$
D M F=\sqrt{\frac{\left(2 \alpha \beta \xi_{t}\right)^{2}+\left(\alpha^{2}-\beta^{2}\right)^{2}}{a^{2}+b^{2}}}
$$

where

$$
\begin{aligned}
& \beta=\frac{\omega}{\omega_{s}}, \quad \alpha=\frac{\omega_{t}}{\omega_{s}}, \quad \xi_{s}=\frac{c_{s}}{2 m_{s} \omega_{s}}, \quad \xi_{t}=\frac{c_{t}}{2 m_{t} \omega_{t}}, \quad \mu=\frac{m_{t}}{m_{s}} \\
& a=\left[2 \beta \alpha \xi_{t}\left(1-\beta^{2}+\mu \alpha^{2}\right)+2 \xi_{s} \beta\left(\alpha^{2}-\beta^{2}\right)\right] \\
& b=\left[\alpha^{2}-\left(1+\alpha^{2}+\mu \alpha^{2}+4 \alpha \xi_{s} \xi_{t}\right) \beta^{2}+\beta^{4}\right]
\end{aligned}
$$

The given parameters in Eq. (9) are previously defined in Eq. (4).

The optimum tuning ratio of a NT-TMD are given by in references (Liu and Coppola, 2010; Anh and Nguyen, 2014), respectively.

$$
\begin{gathered}
\alpha=\sqrt{\frac{1-4 \xi_{s}^{2}}{1-\mu}} \\
\alpha=\frac{1}{\sqrt{1-\mu}\left(\sqrt{1+\frac{\pi^{2}}{\left(\pi^{2}-2\right)^{2}} \xi_{s}^{2}}+\frac{\pi}{\pi^{2}-2} \xi_{s}\right)}
\end{gathered}
$$


Although they obtained the optimum values of the tuning ratio, used the formula $\xi_{t}=(3 \mu /(8-4 \mu))^{0.5}$ suggested by Ren (2001) for the damping ratio of NT-TMD. The values obtained from this formula is not optimal as it is recommended for the undamped main structure.

\section{OPTIMIZATION OF NT-TMD}

General formulation of the optimization problem can be expresses as follow

$$
\min \operatorname{DMF}(p) \quad p^{L} \leq p \leq p^{U}
$$

where $p=\left[\xi^{\text {opt }} \alpha^{\text {opt }}\right]$ is termed the design vector and $\operatorname{DMF}(p)$ denotes the objective function. $p^{U}=[0.51 .2]$ and $p^{L}=[00.8]$ are the upper and lower bound vectors of the design variables, respectively. These bounds are chosen based on the literature (Anh and Nguyen, 2014).

It was assumed that the mass ratio $\mu$ of the control devices is known. Therefore, two design variables (i.e., $\xi^{\text {opt }}$ and $\alpha^{\text {opt }}$ ) are needed for the optimization of both devices. The following ranges for these parameters for are given by

$$
\alpha^{o p t}=\frac{\omega_{t}}{\omega_{s}}, \quad \xi^{o p t}=\frac{c_{t}}{2 m_{t} \omega_{t}}, \quad \mu=\frac{m_{t}}{m_{s}}
$$

where $\xi^{\text {opt }}$ and $\alpha^{\text {opt }}$ denote the damping ratio and the optimum tuning ratio for considered control devices.

The optimization problem addressed in this study is solved by using the hybrid pattern search (HPS) technique which depends on the pattern search (PS) and genetic algorithm (GA). Although PS is widely used in the solution of different engineering problems (Wetter and Polak, 2005; Karakaya and Soykasap, 2009; Amiri et al., 2011; Baghari and Amini, 2013), it is rarely used in the optimization of the tuned mass dampers. Therefore, it is preferred in the solution of the optimization problem in this study. 


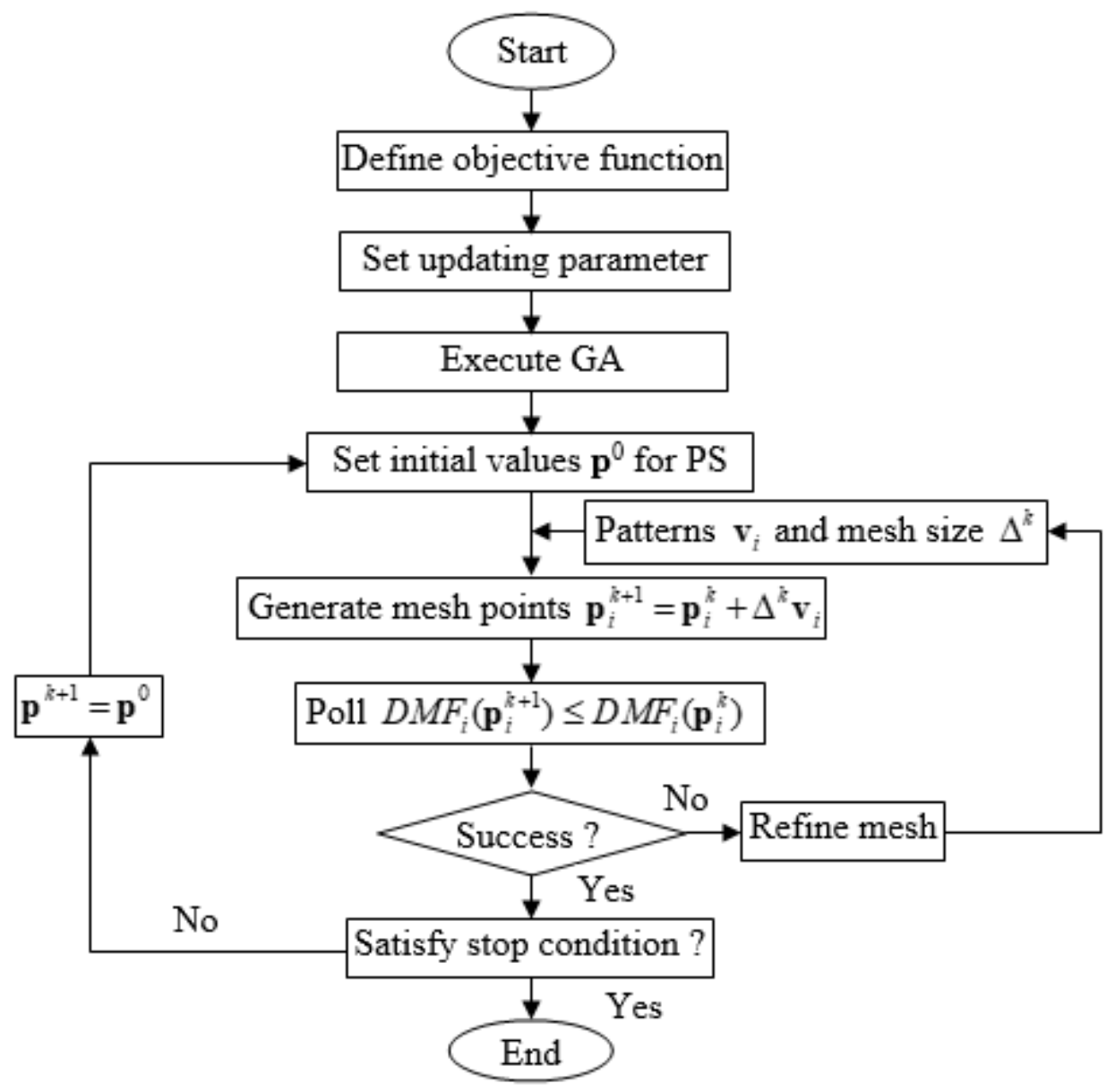

Figure 2:

Flowchart of present optimization method

The PS method consists of two steps, namely the pattern step and the poll step. The pattern consists of a set vectors $\mathbf{v}_{\mathbf{i}}\left(i=1,23\right.$ and 4) such as $\mathbf{v}_{\mathbf{1}}=\left[\begin{array}{ll}1 & 0\end{array}\right], \mathbf{v}_{\mathbf{2}}=\left[\begin{array}{ll}0 & 1\end{array}\right], \mathbf{v}_{\mathbf{3}}=\left[\begin{array}{ll}-1 & 0\end{array}\right]$ and $\mathbf{v}_{\mathbf{4}}=\left[\begin{array}{l}0 \\ -\end{array}\right.$ 1]. A mesh is then created around the search point with the help of the pattern vector. It is expressed as follows:

$$
\mathbf{p}_{i}^{k+1}=\mathbf{p}_{i}^{k}+\Delta^{k} \mathbf{v}_{\mathbf{i}}
$$

where $\Delta^{k}$ denotes the mesh size.

The PS polls the mesh points in the current mesh by calculating their objective function values. When the algorithm finds a point whose objective function value is smaller than that of the current point, it stops polling the mesh points. In this case, the poll is considered succeeded and the point found becomes the current point in the next step. Objective function values and mesh points are calculated by the algorithm up to the point at which it stops the poll.

In Fig. 3, the optimum tuning ratios obtained from the presented method are compared to the results of different optimization methods such as $H_{\infty}$ optimization method and the fixedpoint theory. According to these figures, it is observed that the results show great similarity. The present method gives slightly greater tuning ratios than those of Anh and Nguyen (2014). 
Compared with the other two methods for $\xi_{s}=2 \%$ and $5 \%$, the maximum difference for any tuning ratio value is seen to be $0.14 \%$ and $0.75 \%$, respectively.

Fig. 4 shows the relation curves between the mass ratio and the optimum damping ratio. As can be seen, the present method gives greater damping ratios than those of the other method. Compared with the other both methods for $\xi_{s}=2 \%$ and 5\%, the maximum difference for any optimum damping value is seen to be $7.84 \%$ and $11.97 \%$, respectively. Since the damping ratios used for the other methods are not optimum, the magnitude of the difference is larger than the tuning ratio.

In the below figures, Ref. (1) and Ref. (2) indicates Liu and Coppola (2010) and Anh and Nguyen (2014), respectively. $H_{\infty}$ optimization method and the fixed-point theory are used in these references.
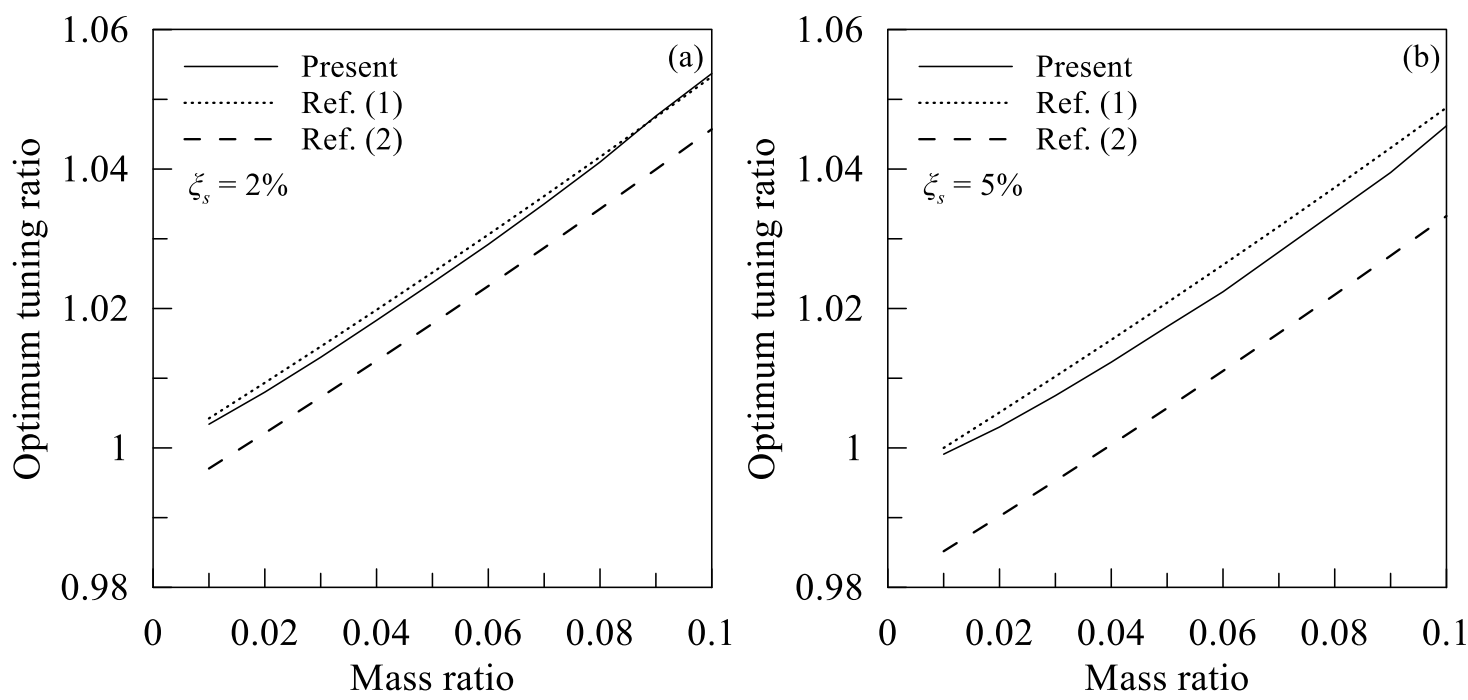

Figure 3:

The change of optimum tuning ratio with respect to mass ratio
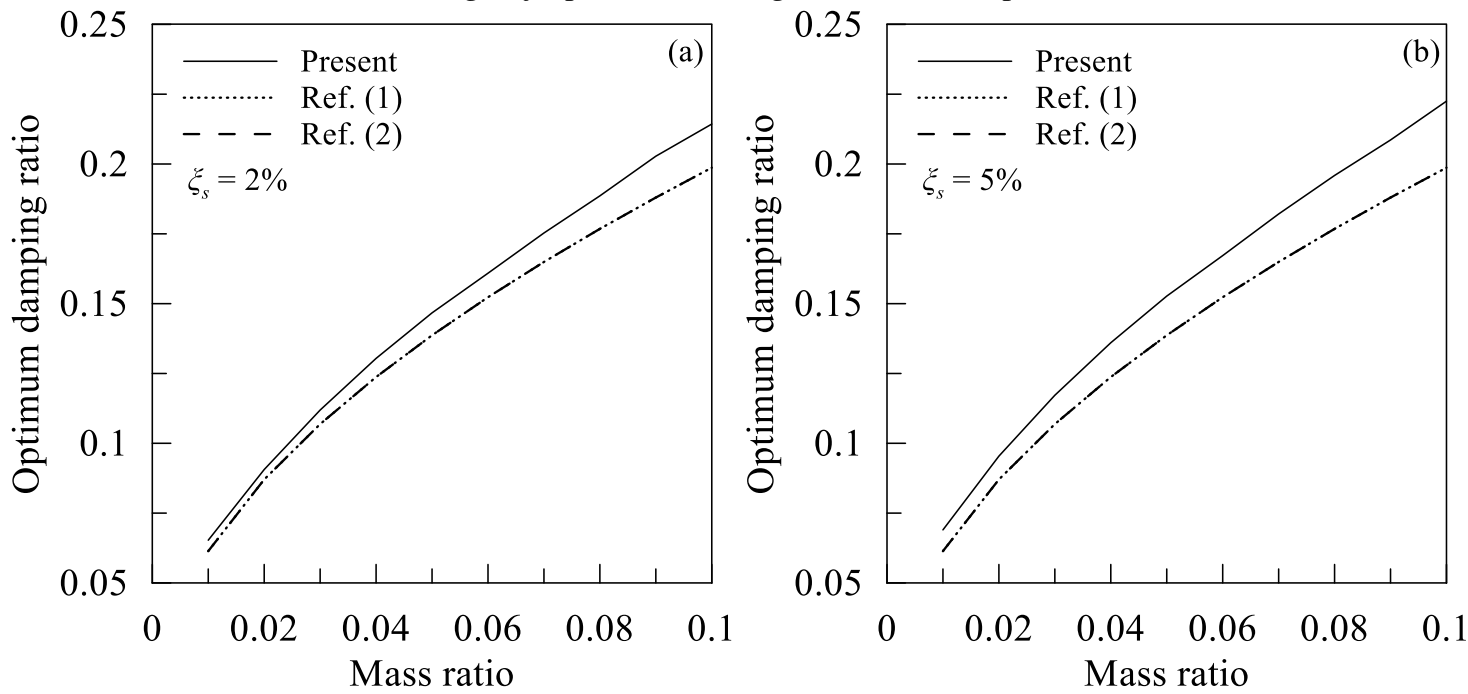

Figure 4:

The change of optimum damping ratio with respect to mass ratio 

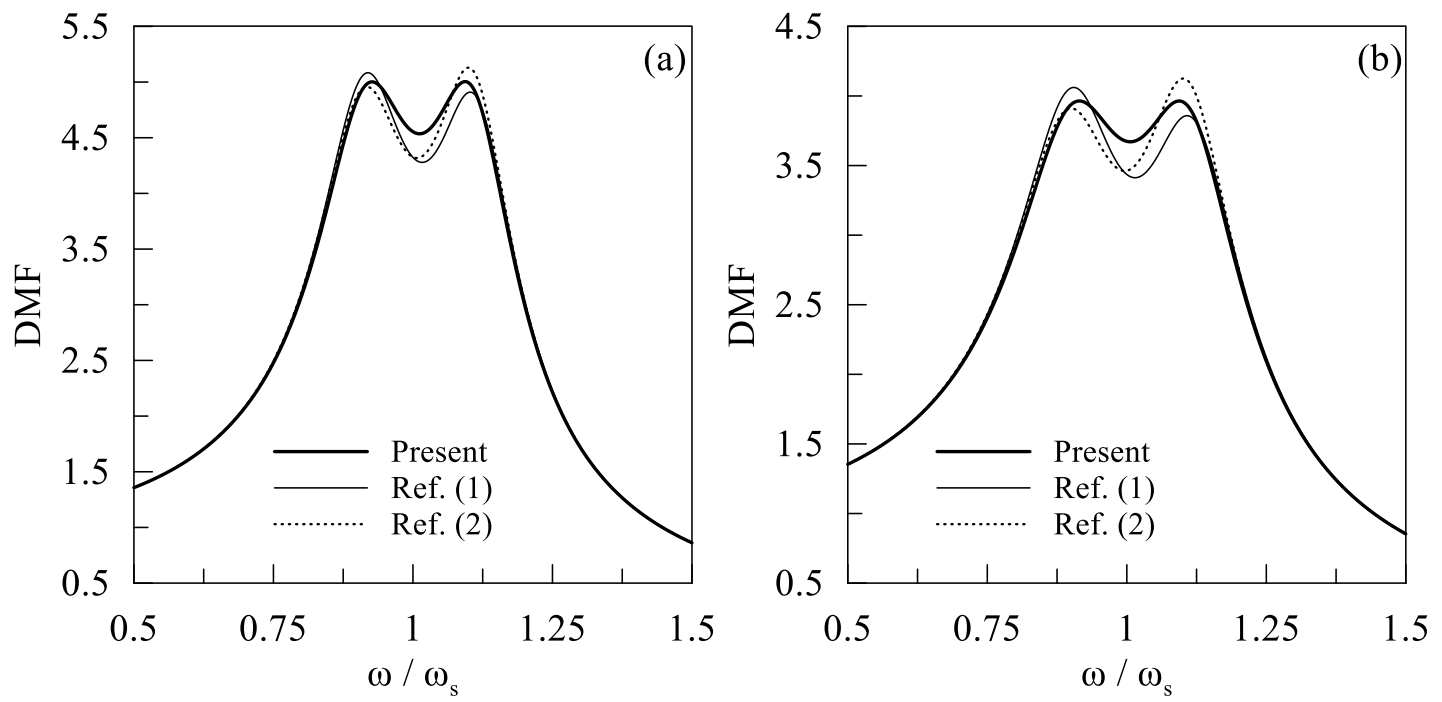

Figure 5:

Response amplitude DMF of the structure with the NT-TMD for $\mu=0.05$ :(a) $\xi_{s}=2 \%$; (b)

$$
\xi_{s}=5 \%
$$

Table 1 Comparison of optimization results with the literature values where $\mu=0.05$

\begin{tabular}{llllllll}
\hline Variables/ & \multicolumn{3}{c}{$\xi_{s}=2 \%$} & & \multicolumn{3}{c}{$\xi_{s}=5 \%$} \\
\cline { 2 - 4 } \cline { 7 - 8 } function & Present & Ref. (1) & Ref. (2) & & Present & Ref. (1) & Ref. (2) \\
\hline$\alpha_{\text {opt }}$ & 1.0237 & 1.0252 & 1.0178 & & 1.0174 & 1.0208 & 1.0057 \\
$\xi_{\text {opt }}$ & 0.1467 & 0.1368 & 0.1368 & & 0.1527 & 0.1368 & 0.1368 \\
max. DMF & 5.0040 & 5.0835 & 5.1293 & & 3.9640 & 4.0610 & 4.1253 \\
\hline
\end{tabular}

In Figs. 5(a) and (b), response amplitude DMF of the structure with the NT-TMD for the different damping ratios is shown. The peak responses and optimal parameters are also given in Table 1. As can see from Table 1 and Fig. 5, NT-TMD designed with the presented method has better control performance than other methods. 


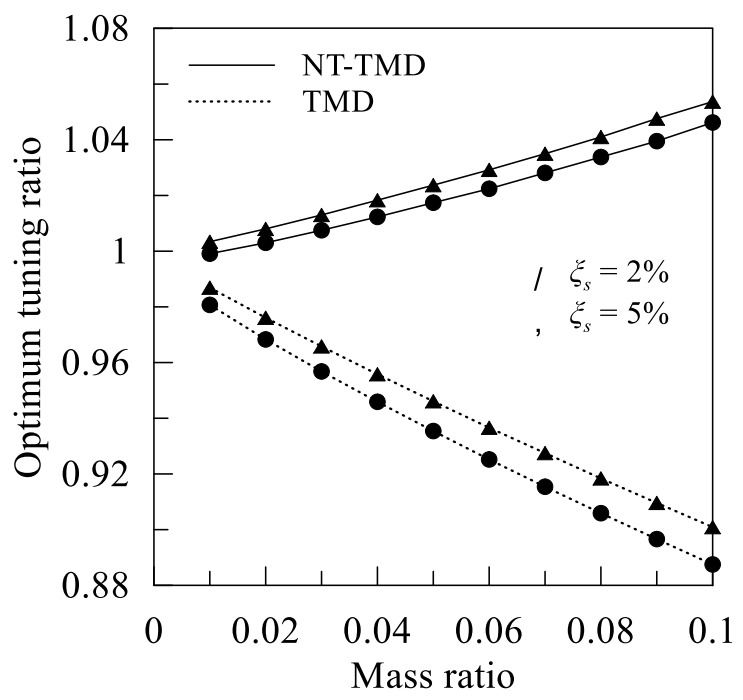

Figure 6:

The optimum tuning ratios obtained for different mass ratios

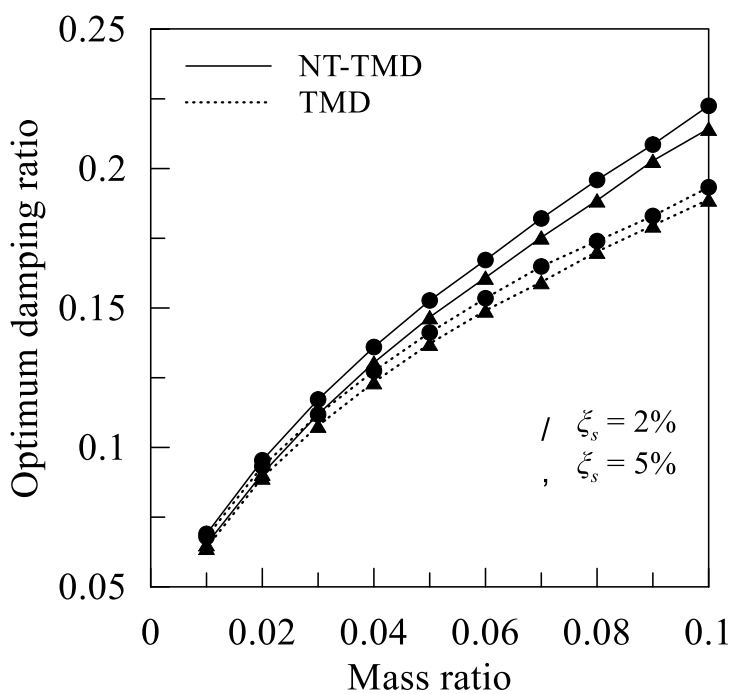

Figure 7:

The optimum damping ratios obtained for different mass ratios

The optimum tuning ratios with different mass ratios are given in Fig. 6. Fig. 6 depicts the optimum values of TMD are less than that of NT-TMD. Figure 6 also shows that the tuning ratio increases with the decrease in the damping ratio of the structure.

The optimum damping ratios of the both devices for various mass ratios are shown in Fig. 7. As can see from Fig. 7, the optimum damping ratio of the TMD is smaller than that of NTTMD. Fig. 7 also depicts as the damping ratio of the main system and the mass ratio increase, the damping ratio of both devices increases.

\section{NUMERICAL ANALYSIS}

Numerical analysis is carried out to investigated control effectiveness of the NT-TMD in suppressing the peak DMF values of the structure for two different structural damping ratios (i.e., $\xi_{s}=2 \%$ and $5 \%$ ). 
Fig. 8 shows the displacement responses of the structure with the NT-TMD and TMD for $\mu=0.05$. Fig. 8 indicates that the optimum NT-TMD is more effective than classical TMD in suppressing the vibrations around the resonance.

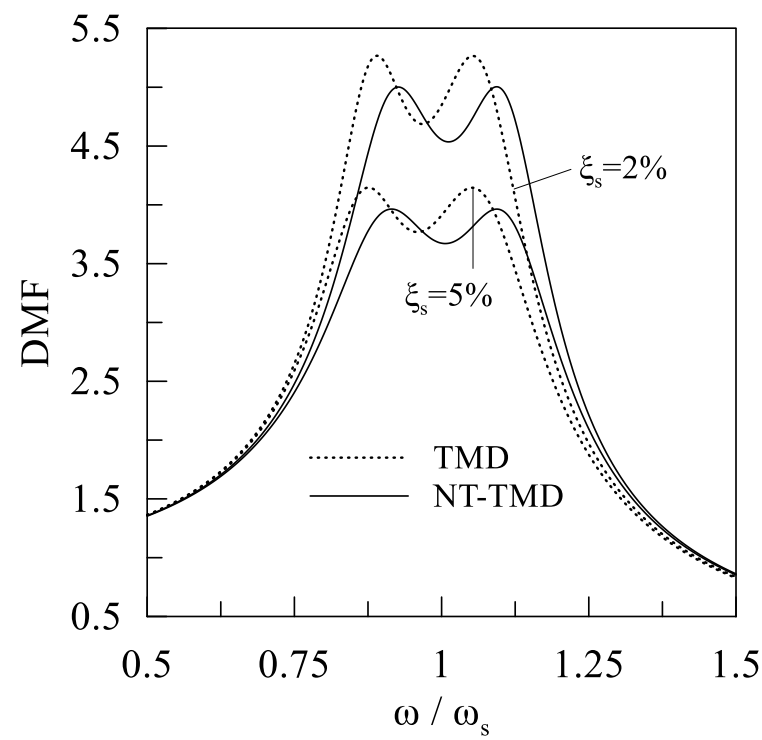

Figure 8:

Comparison of DMF response of the structure with the both devices

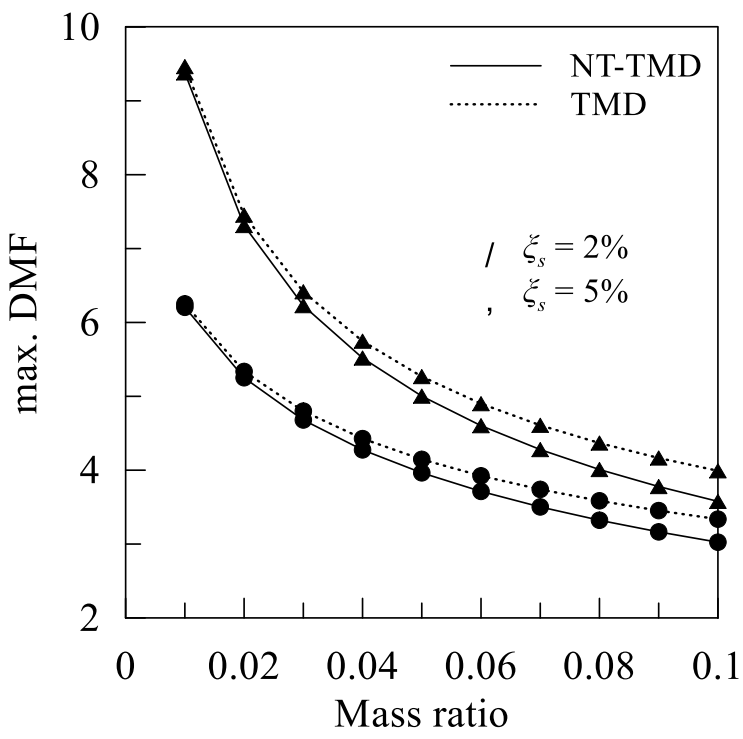

Figure 9:

The maximum DMF values obtained against different mass ratios

For further validation, the maximum DMF curves against the mass ratio for both devices are given in Fig. 9. As seen from this figure, if the mass ratio is bigger than 0.03, NT-TMD offers higher effectiveness than TMD. Thus, it is recommended that NT-TMD has a mass ratio greater than 0.03 for high control performance. 


\section{CONCLUSIONS}

A number of numerical analyzes are carried out to investigate the effectiveness of nontraditional TMDs attached to a damped main structure due to harmonic excitation. Hybrid pattern search (HPS) technique is used to obtain optimum values. The conclusions can be summarized as follows.

- The optimum values obtained for NT-TMD are greater than those obtained for TMD.

- The increase in the mass ratio increases the tuning ratio of NT-TMD while decreases the tuning ratio of TMD.

- The increase in the mass ratio causes the damping ratios of both control devices to increase.

- When the mass ratio is bigger than 0.03, NT-TMD offers higher effectiveness than TMD. Thus, it is recommended that NT-TMD has a mass ratio greater than 0.03 for high control effectiveness.

\section{CONFLICT OF INTEREST}

The authors confirm that there is no known conflict of interest or common interest with any institution/organization or person.

\section{AUTHOR CONTRIBUTION}

Onur ARAZ: Determination of design processes of the study, data analysis and interpretation, reviewing the intellectual content, final approval and full responsibility of the study.

Volkan KAHYA: Reviewing the intellectual content, final approval and full responsibility of the study.

\section{REFERENCES}

1. Amiri, G.G., Razzaghi, S.A.S. and Bagheri, A. (2011) Damage detection in plates based on pattern search and Genetic algorithms, Smart Structures and Systems, 7(2), 117-132. doi: 10.12989/sss.2011.7.2.117

2. Anh, N.D. and Nguyen, N.X. (2014) Design of non-traditional dynamic vibration absorber for damped linear structures, Proceedings of the Institution of Mechanical Engineers, Part C: Journal of Mechanical Engineering Science, 228, 45-55. doi: $10.1177 / 0954406213481422$

3. Anh, N.D., Nguyen, N.X. and Quan, N.H. (2016) Global-local approach to the design of dynamic vibration absorber for damped structures, Journal and Vibration Control, 22, 1-20. doi: $10.1177 / 1077546314561282$

4. Araz, O. (2020) Effect of detuning conditions on the performance of non-traditional tuned mass dampers under external excitation, Arch. Appl. Mech., 90, 523-532. doi: 10.1007/s00419-019-01623-Z

5. Araz, O. and Kahya, V. (2018) Effects of manufacturing type on control performance of multiple tuned mass dampers under harmonic excitation, Journal of Structural Engineering \& Applied Mechanics, 1(3), 117-27. doi:10.31462/jseam.2018.03117127

6. Araz, O. and Kahya, V. (2020) Series tuned mass dampers in control of continuous railway bridges, Struct. Eng. Mech., 73(2), 133-141. doi: 10.12989/sem.2020.73.2.133 
7. Araz, O. and Kahya, V. (2021) Design of series tuned mass dampers for seismic control of structures using simulated annealing algorithm, Archive of Applied Mechanics, 91, 43434359. doi: 10.1007/s00419-021-02013-0

8. Asami, T., Nishihara, O. and Baz, A.M. (2002) Analytical solutions to $\mathrm{H}_{\infty}$ and $\mathrm{H}_{2}$ optimization of dynamic vibration absorbers attached to damped linear systems, Journal of Vibration and Acoustics, 124, 284-295. doi: 10.1115/1.1456458

9. Bagheri, A. and Amini, F. (2013) Control of structures under uniform hazard earthquake excitation via wavelet analysis and pattern search method, Structural Control \& Health Monitoring, 20(5), 671-685. doi: 10.1002/stc.510

10. Bakre, S.V. and Jangid, R.S. (2004) Optimum multiple tuned mass dampers for baseexcited damped main system, Int. J. Struct. Stab. Dyn., 4(4), 527-542.

doi: $10.1142 / \mathrm{S} 0219455404001367$

11. Cheung, Y.L. and Wong, W.O. (2009) Design of a non-traditional dynamic vibration absorber (L), Journal of the Acoustical Society of America, 126, 564-567. doi: $10.1121 / 1.3158917$

12. Cheung, Y.L. and Wong, W.O. (2011) $\mathrm{H}_{2}$ optimization of a non-traditional dynamic vibration absorber for vibration control of structures under random force excitation, Journal of Sound and Vibration, 330, 1039-1044. doi: 10.1016/j.jsv.2010.10.031

13. Cheung, Y.L. and Wong, W.O. (2011) H-infinity optimization of a variant design of the dynamic vibration absorber-Revisited and new results, Journal of Sound and Vibration, 330,3901-3912. doi: 10.1016/j.jsv.2011.03.027

14. Dell'Elce, L., Gourc, E. and Kerschen, G. (2018) A robust equal-peak method for uncertain mechanical systems, J. Sound Vib., 414, 97-109. doi: 10.1016/j.jsv.2017.10.038

15. Den Hartog, J.P. (1956) Mechanical Vibrations, McGraw-Hill, New York

16. Esen, İ. and Koç, M.A. (2015) Optimization of a passive vibration absorber for a barrel using the genetic algorithm, Expert Syst. Appl., 42, 894-905. doi: 10.1016/j.eswa.2014.08.038

17. Frahm, H. (1909) Device for Damped Vibration of Bodies. U.S. Patent No. 989958.

18. Fujino, Y. and Abe, M. (1993) Design formulas for tuned mass dampers based on a perturbation technique, Earth. Eng. Struct. Dyn., 22(10), 833-854.

doi: $10.1002 /$ eqe. 4290221002

19. Jangid, R.S. (1999) Optimum multiple tuned mass dampers for base-excited undamped system, Earthq. Eng. Struct. Dyn., 28(9), 1041-1049.

doi: 10.1002/(SICI)1096-9845(199909)28:9<1041::AID-EQE853>3.0.CO;2-E

20. Kahya, V. and Araz, O. (2017) Series tuned mass dampers in train-induced vibration control of railway bridges, Structural Engineering and Mechanics, 61, 453-461.

doi: 10.12989/sem.2017.61.4.453

21. Kahya, V. and Araz, O. (2019) A sequential approach based design of multiple tuned mass dampers under harmonic excitation, Sigma Journal of Engineering and Natural Sciences, 37, 225-239.

22. Kahya, V. and Araz, O. (2020) A simple design method for multiple tuned mass dampers in reduction of excessive vibrations of high-speed railway bridges, Journal of the Faculty of Engineering and Architecture of Gazi University, 35(2), 607-618.

doi: 10.17341/gazimmfd.493102 
23. Karakaya, S. and Soykasap, O. (2009) Buckling optimization of laminated composite plates using genetic algorithm and generalized pattern search algorithm, Structural and Multidisciplinary Optimization, 39(5), 477-486. doi: 10.1007/s00158-008-0344-2

24. Koc, M.A. (2020a) Implementation of a Vibration Absorbers to Euler-Bernoulli Beam and Dynamic Analysis of Moving Car, Academic Platform Journal of Engineering and Science, 8, 523-532. doi: 10.21541/apjes.662708

25. Koc, M.A. (2020b) Fuzzy Logic Control of Vibrations due to Interaction One DOF Vehicle and Flexible Structure with Tuned Mass Damper, Journal of Smart Systems Suspension Research, 1, 1-10.

26. Li, C. (2002) Optimum multiple tuned mass dampers for structures under the ground acceleration based on DDMF and ADMF, Earthquake Engineering and Structural Dynamics, 31, 897-919. doi: 10.1002/eqe.128

27. Liu, K. and Liu, J. (2005) The damped dynamic vibration absorbers: revisited and new result, Journal of Sound and Vibration, 284, 1181-1189. doi: 10.1016/j.jsv.2004.08.002

28. Liu, K. and Coppola, G. (2010) Optimal design of damped dynamic vibration absorber for damped primary systems, Transactions of the Canadian Society for Mechanical Engineering, 34, 119-135. doi: 10.1139/tcsme-2010-0008

29. Marano, G.C. and Greco, R. (2011) Optimization criteria for tuned mass dampers for structural vibration control under stochastic excitation, Journal and Vibration Control, 17, 679-688.doi: 10.1177/1077546310365988

30. Marano, G.C., Greco, R., Trentadue, F. and Chiaia, B. (2007) Constrained reliability-based optimization of linear tuned mass dampers for seismic control, Int. J. Solids Struct., 44(2223), 7370-7388. doi: 10.1016/j.ijsolstr.2007.04.012

31. Mate, N.U., Bakre, S.V. and Jaiswal, O.R. (2017) Seismic pounding response of singleddegree-of-freedom elastic and inelastic structures using passive tuned mass damper, International Journal of Civil Engineering, 15, 991-1005. doi: 10.1007/s40999-017-0178-7

32. Matta, E. (2015) Seismic effectiveness of tuned mass dampers in a life-cycle cost perspective, Earthquakes and Structures, 9(1), 73-91. doi: 10.12989/eas.2015.9.1.073

33. Mrabet, E., Guedri, M., Ichchou, M.N., Ghanmi, S. and Soula, M. (2018) A new reliability based optimization of tuned mass damper parameters using energy approach, Journal and Vibration Control, 24, 153-170. doi: 10.1177/1077546316636361

34. Nigdeli S.M. and Bekdas, G. (2014) Optimum tuned mass damper approach for adjacent structures, Earthquakes and Structures, 7(6), 1071-1091. doi: 10.12989/eas.2014.7.6.1071

35. Ormondroyd, J. and Den Hartog, J.P. (1928) The theory of the dynamic vibration absorber, Transactions of ASME Journal of Applied Mechanics, 50, 9-22.

36. Ren, M.Z. (2001) A variant design of the dynamic vibration absorber, Journal of Sound and Vibration, 245, 762-770. doi: 10.1006/jsvi.2001.3564

37. Ruge, G. and Wagner, N. (2020) Design of tuned mass dampers for damped structures with uncertain excitation, Bautechnik, 97, 737-743. doi: 10.1002/bate.202000024

38. Tsai, H.C. (1995) The effect of tuned-mass dampers on the seismic response of baseisolated structures, Int. J. Solids Struct., 32(8-9), 1195-1210. doi: 10.1016/00207683(94)00150-U

39. Yazdi, H.A., Saberi, H. and Hatemi, F. (2016) Designing optimal tuned mass dampers using improved harmony search algorithm, Adv. Struct. Eng., 19(10), 1620-1636.

doi: $10.1177 / 1369433216646018$ 
40. Yucel, M., Bekdaş, G., Nigdeli, S.M. and Sevgen, S. (2019) Estimation of optimum tuned mass damper parameters via machine learning, J. Build. Eng., 26, 100847. doi: 10.1016/j.jobe.2019.100847

41. Yuan, M., Liu, K. and Sadhu, A. (2018) Simultaneous vibration suppression and energy harvesting with a non-traditional vibration absorber, Journal Intelligent Material Systems and Structures, 29, 1748-1763. doi: 10.1177/1045389X17754263

42. Warburton, G.B. (1982) Optimum absorber parameters for various combinations of response and excitation parameters, Earthq. Eng. Struct. Dyn., 10(3), 381-401. doi: $10.1002 /$ eqe. 4290100304

43. Wetter, M. and Polak, E. (2005) Building design optimization using a convergent pattern search algorithm with adaptive precision simulations, Energy and Buildings, 37(6), 603612.doi: 10.1016/j.enbuild.2004.09.005

44. Wong W.O. and Cheung, Y.L. (2008) Optimal design of a damped dynamic vibration absorber for vibration control of structure excited by ground motion, Engineering Structures, 30,282-286. doi: 10.1016/j.engstruct.2007.03.007 